\title{
Monstros nas fronteiras da cultura: das alteridades impensáveis
}

\author{
Monsters at the borders of culture: \\ on unthinkable otherness
}

Elizangela Aparecida SOARES ${ }^{1}$

Este artigo discute aspectos da concepção sobre "raças monstruosas" que, no imaginário antigo e medieval, habitavam as bordas do mundo conhecido. Com isso, espera-se explicitar um tipo de construção do "outro" - sua identidade e representação -, via imaginário do monstro, isto é, a forma literal na qual estranhas criaturas incorporam a diferença/alteridade. Parte-se da premissa de que monstros operam primariamente em formas de imaginário que são mobilizadas por estratégias de representação. Dito de outra maneira, a corporeidade anormal e híbrida dos monstros inventados tem consequências reais para a percepção (horror e fascínio, rejeição e reconhecimento) nas relações eu-outro que se concretizam no mundo tangível. Desse modo, a conjugação entre fisicalidade, expressões de identidade e manutenção de fronteiras determina, entre outros comportamentos, visões pré-concebidas e distorcidas do outro e sua cultura, assim como cria certos estereótipos que são perpetuados pela cristalização do que uma vez fora apenas uma manifestação do imaginário.

Palavras-chave: Alteridade. Identidade. Raças monstruosas. Representação.

\section{Abstract}

This paper discusses aspects of the notion of "monstrous races" that used to inhabit the edges of the known world in ancient and medieval imagination. Thus, it is expected to make explicit a type of construction of the "other" - their identity and representation - via imaginary of the monster, that is, the literal form in which strange creatures embody difference/otherness. The paper starts from the premise that monsters operate primarily in forms of imagery that are mobilized by strategies of representation. In other words, the abnormal and hybrid corporeality of invented monsters has real consequences for perception (horror and fascination, rejection and recognition) in the self-other relationships that take shape in the tangible world. In this way, the combination of physicality, identity expressions and border maintenance determines, among other behaviors, preconceived and distorted views of the other and their culture, as well as creates certain stereotypes perpetuated by the crystallization of what once had been only a manifestation of the imaginary.

Keywords: Otherness. Identity. Monstrous races. Representation. 


\section{In t rod u çã o}

Identidades são erigidas pela marcação e dependência da diferença, por um jogo de oposições, quase sempre assimétricas, que implica processos de inclusão e de exclusão. Trata-se, em última análise, daquilo que é e daquilo que não é2. Por essa razão, as sociedades - antigas, medievais e modernas -, se definem não apenas pelo que a introspecção concede, mas igualmente por meio de um olhar "para fora", para o que elas percebem como "os outros": outras raças, outras culturas, outras espécies. É por intermédio da representação ${ }^{3}$ e da comparação com esses outros que elas estabelecem as qualidades pelas quais desejam ser definidas, fazendo surgir binarismos como normal-anormal, bom-mau, moral-imoral, civilizado-bárbaro, ordinário-exótico, humano-monstro.

Embora a relação eu(nós)-outro possa ter significados diferentes nos diversos campos do conhecimento, o outro não está simplesmente dado em nenhum desses contextos. Ele não é percebido ou encontrado, mas construído; uma ficção criada pelo eu. Seu lugar de invento é a fronteira ${ }^{4}$, uma espécie de zona imaginária de transição onde os diferentes negociam suas identidades mutuamente. Decorre dessa negociação liminar, do diálogo entre alteridades, que "uma mudança no valor do 'eu' invariavelmente altera a imagem do 'outro' e vice-versa; e qualquer mudança altera a natureza da diferença que eles constituem e pela qual são constituídos [...] não pode haver uma definição final da relação entre 'nós' e os 'outros'" (Crick, 1976, p. 165).

Nessa dança das alteridades situam-se as representações, os modos de significar. Assim, se por um lado é possível aprender muito sobre uma sociedade pela observação do que ela admira ou reverencia, por outro, aquilo de que ela tem medo e a maneira como o representa também têm muito a dizer a seu respeito. Um modo bastante antigo de materializar os temores, de dar cara e corpo às ameaças, é representá-las pela criação de monstros cuja matéria prima é uma alteridade que marca os limites entre o que é considerado bom e normal e aquilo que, desconhecido ou rejeitado, é interpretado como desviante e anormal. Mais diretamente, monstros seriam metáforas para realidades sociais e existenciais desagradáveis ${ }^{5}$. Embora as mesmas sociedades que os criam busquem também negá-los ou expurgá-los, monstros funcionam como construções ideológicas que explicitam a forma como elas pensam e operam, especialmente em relação ao diferente. Cada cultura tem suas próprias preocupações e temores, suas próprias definições de "normal" e seu próprio olhar para a realidade. Como observa Atherton (1998, p. X), os monstros "são definidos em relação a comunidades e seus padrões do que é bom, aceitável, normal ou natural". A monstruosidade está, portanto, profundamente conectada com a cultura que a produz, camufla, marginaliza e resiste. Monstros costumam surgir do desejo de domesticar e, assim, desautorizar aquilo que uma cultura considera ameaçador.

Este texto se ocupa de monstros, alteridades impensáveis, modos de significar. Para isso, recorre ao (agora) longínquo e estranho entendimento de que os confins do mundo eram habitados por raças exóticas e monstruosas não apenas de animais, mas também (e sobretudo) de "homens". Nesse percurso observa-se monstros de dentro e de fora, o esforço nos registros de escritores proeminentes da antiguidade clássica, tardia e do medievo para tipificar a diferença e, no caso daqueles que eram cristãos, para também encontrar seu lugar no enredo salvífico e função na criação como advertência aos perigos

\footnotetext{
2 Para uma discussão sobre o conceito de identidade, veja os capítulos de Silva (2014) e Woodward (2014).

3 O termo "representação" é aqui empregado no sentido dado por Stuart Hall, isto é, representação como significação, atuando simbolicamente para classificar o mundo e nossas relações dentro dele; como aquilo que conecta o sentido e a linguagem à cultura (Hall, 2003).

${ }^{4}$ Emprego o conceito de fronteira como proposto por Hanciau (2005, p. 135): "Antes de serem marcos físicos ou naturais, as fronteiras são, sobretudo, o produto da capacidade imaginária de refigurar a realidade a partir de um mundo paralelo de sinais que guiam o olhar e a apreciação, por intermédio dos quais os homens e as mulheres percebem e qualificam a si mesmos, o corpo social, o espaço e o próprio tempo".

${ }^{5}$ Devo esse argumento a Grixti (1989) e seus estudos sobre os contextos culturais da ficção de horror.
} 
da queda original. Assim, os monstros permaneciam em seus papeis de representações convenientes do inconveniente: deformidades e deficiências físicas, o feminino, o diferente, o desconhecido, o pecado.

\section{Das raças monstruosas - maravilhas e exotismo nos limites do mundo}

Não cabe e nem é o objetivo deste escrito traçar uma história do monstro e do monstruoso/ monstruosidade que dele derivam. Importa, por hora, ter no horizonte que (1) monstros frequentam a imaginação humana desde sempre, (2) que eles são culturalmente determinados e que (3) sua existência encarna terrores tanto individuais como coletivos. Cabe, contudo, visualizá-los em perspectiva histórica. Para os gregos antigos, essa expressão pertencia à esfera do cotidiano: monstros narravam a possibilidade de superação da ordem pelo caos, de a irracionalidade prevalecer sobre a razão; a potencial vitória da natureza contra as civilizações humanas; a pouco compreendida natureza do feminino em contraste com o masculino ${ }^{6}$. Para romanos, por outro lado, essas criaturas emprestavam feições a preocupações e questões de identidade: as fronteiras, físicas e imaginárias, entre o civilizado e o bárbaro; o oposto da sociedade racional e ordenada idealizada; uma ameaça latente e um lembrete constante do que é desejável e daquilo que não é.

Os monstros da antiguidade clássica, da antiguidade tardia e do medievo viviam tanto dentro como fora da sociedade. Os de "dentro" designavam pessoas que gravitavam à margem da norma biológica7. Isso pode ser percebido, por exemplo, em "Da Geração dos Animais", em que Aristóteles emprega o termo "monstruosidade" para descrever formas de excesso corporal, deficiência ou deslocamento. Essa caracterização não se esgotava em corpos malformados por doenças, acidentes ou nascimentos. Mais amplamente, tratava-se de uma representação de todos os seres percebidos como um desvio do curso comum da natureza (Aristotle, 1943, 767b.5-10). Alguns séculos mais tarde, o jurisconsulto romano Ulpiano afirmaria algo na mesma direção:

Quando uma mulher gerar uma criança que é deformada, ou um monstro, ou defeituosa, ou que tenha algo incomum em sua aparência ou voz, e que não tenha semelhança com um ser humano, mas pareça mais um animal do que um homem, pode-se perguntar: será de algum benefício para ela trazer uma criatura assim ao mundo? (Watson, 1998, 50.16.135).

Tanto em Aristóteles como em Ulpiano, a monstruosidade se apresenta como um fenômeno externo, corporal, centrado na oposição entre natural e não natural, que serve para justificar uma série de atitudes em relação a grupos específicos de pessoas (mulheres e deficientes físicos em especial), esses "outros inapropriados" (Haraway, 2020, p. 465) ${ }^{8}$, desviantes da biologia aceita como ordinária.

Reconhecido o que representa esse salto temporal, a Idade Média cristã entretinha uma relação utilitarista com esses monstros de dentro. Em sua história social da deficiência, Hughes (2019) explica que, nesse período, o corpo desviante era um sistema nuançado de comunicação moral que mediava entre o sagrado e profano, o miraculoso e o mundano, condenação e salvação, graça e desgraça. A estrutura moral

\footnotetext{
6 Aristóteles, por exemplo, considerava qualquer desvio da morfologia do corpo masculino "normal" como um tipo de monstruosidade (Aristotle, 1943, 728a.18; 737a.27). A mulher era, nessa concepção, um tipo de homem que não deu certo.

7 Sobre a questão da deficiência física como desvio biológico, veja Garland (2010).

8 Tomo a expressão "outros inapropriados" (inappropriate/d others) de Donna Haraway consciente de que ela a emprega em um sentido muito mais amplo, profundo e orgânico.
} 
da invalidação da deficiência não apenas se baseava em um conjunto de significados pejorativos, mas era também essencial para um complexo sistema de caridade - este, um aparelho instrumental de bem-estar que beneficiava mais a comunidade sem deficiências do que os deficientes. Esse sistema não tinha a ver com compaixão e altruísmo puros, mas com oportunidades de "purificação" para não deficientes que, ao colocarem certas ações em curso, podiam obter glórias celestiais pelos seus atos misericordiosos. Dito de outra maneira, a deficiência era uma plataforma para a salvação dos não deficientes. Nesse cenário, a doutrina da redenção sugeria que "perfeição" e deficiência não eram mutuamente excludentes (como era o caso no mundo antigo), tendo em vista que a última era remível no momento em que a morte ou o miraculoso batessem à porta?.

Por sua vez, os monstros "de fora" eram os habitantes das regiões desconhecidas que estão nas fronteiras do mundo e além delas, fora dos limites da cultura. Para descrevê-los, pôs-se em operação um imaginário poderoso e afeito a estereótipos, que encontrou o seu caminho para dentro das ciências naturais e da geografia, enciclopédias e cosmografias, romances e histórias, mapas e gravuras, miniaturas e esculturas, tornando-se, gradualmente, uma característica regular da mentalidade ocidental. Nessa linha, além do norte da África, o lugar que mais inspirou a imaginação antiga sobre monstros foi a Índia. Um dos primeiros viajantes gregos a chegar a essa região foi Cílax de Carianda, por volta de 515 aEC. Suas descrições de seres humanos monstruosos que aí habitavam, tais como pessoas com orelhas gigantescas ou com uma só perna, teriam inspirado várias outras, incluindo relatos de Heródoto em sua "História", escrita na segunda metade do $5^{\circ}$ século $\mathrm{aEC}^{10}$. Cerca de cinquenta anos mais tarde, no início do $4^{\circ}$ século aEC, um tratado especial sobre a Índia foi publicado por Ctésias de Cnidos, médico na corte de Artaxerxes II, na Pérsia. Graças a ele, pelos próximos mil e quinhentos anos a Índia seria a "terra das maravilhas", um lugar habitado por raças fantásticas de pessoas e animais. Ctésias compilou, tanto de autores gregos quanto persas, muitas histórias conhecidas sobre raças monstruosas, além de haver acrescentado várias outras. Sua Índia era povoada, por exemplo, com pessoas de um único e grande pé; homens com cabeça de cachorro ou mesmo sem cabeça, com o rosto entre os ombros; pessoas com oito dedos nas mãos e nos pés; gigantes; homens com caudas de comprimento extraordinário, entre uma variedade de outros tipos exóticos (Nichols, 2011).

No ano 326 aEC, a Índia foi invadida por Alexandre, o Grande. Seus vários acompanhantes tinham como missão descrever a expedição e os países pelos quais passaram. Como resultado, muitas obras foram escritas (e perdidas). De autoria de Megástenes, geógrafo e diplomata na corte do rei indiano Sandrakottos, o livro mais importante foi produzido após o final das campanhas, tendo sobrevivido como fragmentos em Diodoro Sículo, Estrabo, Plínio, Arriano de Nicomédia, Eliano e outros. São de Megástenes as primeiras declarações abrangentes sobre a geografia da Índia, seus habitantes, instituições sociais e políticas, produtos naturais, história e mitologia. Seu tratado inclui relatos de raças e animais monstruosos repetidos de outros autores, bem como acréscimos consideráveis: há menção a serpentes com asas de morcegos; escorpiões alados de tamanho extraordinário; formigas garimpeiras (reproduzidas de Heródoto); pessoas cujos calcanhares ficam na frente, enquanto o peito do pé e os dedos são virados para trás; homens selvagens sem boca, que vivem do cheiro de frutas e flores; pessoas cujo tempo de vida é de mil anos; pessoas sem narinas, com a parte superior da boca projetando-se muito além do lábio inferior; pessoas que têm orelhas de cachorro e um único olho na testa (McCrindle, 1877).

\footnotetext{
9 O tema da deficiência física no mundo medieval é mais complexo do que isso, sendo este apenas um dos seus aspectos. Para uma compreensão mais ampla do tópico, além de Hughes (2019), veja também Godden e Mittman (2019); Metzler (2013) e Stiker (1999).

10 Por exemplo, sua descrição dos arimaspos como "raça de homens de um só olho" (Hist Ill.116). A esse respeito, veja também Rood (2006, p. 290).
} 
Mas não é de se estranhar que mentes instruídas como Heródoto, Megástenes e Ctésias levassem essas histórias a sério? Não necessariamente. É preciso ter no horizonte que narrativas fabulosas formavam parte da herança cultural grega. Assim, descrições de sátiros, sereias, ciclopes e de homens-cães, bem conhecidas do mundo grego, encontravam suas representações "factíveis" além do oceano. Por outro lado, a própria observação podia fermentar o imaginário. Um bom exemplo é o caso do unicórnio reportado tanto por Ctésias como por Megástenes, que, agora compreende-se, seria um rinoceronte ${ }^{11}$. Em adição, os próprios épicos indianos forneciam uma origem literária para histórias como essas - raças com orelhas compridas, com orelhas de camelo, com os ouvidos nas mãos e com orelhas próximas aos lábios eram frequentemente mencionadas nesses textos. Megástenes mesmo afirma que seu conhecimento sobre "as maravilhas" vinha dos brâmanes, de quem ele não tinha nenhuma razão para desconfiar: narrativas fabulosas estariam bem atestadas demais na tradição indiana, tanto verbal como literária, para não serem levadas em consideração'12.

Uma característica de autores subsequentes foi a reprodução acrítica dos relatos anteriores, agradando com isso o gosto comum dos ouvintes, que esperavam que as terras remotas fossem extraordinárias e surpreendentes. Nesse segmento, uma das principais fontes compilatórias do saber sobre monstros, especialmente no período patrístico do cristianismo e na Idade Média, veio a ser a "História Natural" de Plínio, o Velho (concluída em 77 EC) ${ }^{13}$. Sem nenhuma avaliação daquilo que compila, nela Plínio aceita todas as histórias transmitidas por aqueles que o antecederam.

Em minha descrição dos povos do mundo, falei em grande medida sobre toda a raça humana. Certamente não vou tratar todos os seus costumes e modos, que são incalculáveis e quase tantos quantos os grupos de seres humanos. Contudo, creio que certas raças realmente não podem ser omitidas, especialmente as dos povos que vivem longe do mar. Não tenho dúvidas de que muitos leitores acharão algumas dessas coisas estranhas e incríveis. Quem no mundo, por exemplo, acreditava em etíopes antes de vê-los? Ou o que não é considerado uma maravilha quando pela primeira vez se torna conhecido? Quantas coisas são consideradas impossíveis até que elas aconteçam? (Travillian, 2015, VII.1.6) ${ }^{14}$

"A Índia e as regiões da Etiópia são repletas de maravilhas" (Travillian, 2015, VII.1.21) - é essa a introdução de Plínio às raças monstruosas que supostamente viveriam nessas áreas. A partir daí, assim como outros antes e depois, ele passa a listar monstros e outras maravilhas, com cada entrada fornecendo um padrão básico, composto pelo mesmo inventário de informações: nome, localização, tamanho, breve descrição física e, no caso de alguns, comportamento (Figura 1).

Nos limites mais distantes da Índia, a leste, perto da fonte do Ganges, ele [Megástenes] localiza os astomi, que não têm boca e cujo corpo é coberto de pelos. Eles se vestem de folhagens e vivem apenas do ar que respiram e do odor que inalam pelas narinas. Eles não comem e nem bebem, mas se mantêm apenas com os vários aromas de raízes, flores e maçãs silvestres que carregam consigo em longas jornadas, a fim de que não fiquem sem suprimento do que cheirar. Megástenes diz que um odor muito forte pode matá-los facilmente (Travillian, 2015, VII.2.25).

\footnotetext{
11 No frag. 45 da Indika, Ctésias descreve o unicórnio com o mesmo poder de proteção contra envenenamento atribuído ao rinoceronte na Índia e na China: "Existem jumentos selvagens na Índia do tamanho de cavalos e até maiores. Eles têm o corpo branco, cabeça carmesim e olhos azuis-escuros. Eles têm um chifre no meio da testa com um côvado e meio de comprimento [pouco menos de $70 \mathrm{~cm}$ ]. A parte inferior do chifre, até dois palmos na direção da testa [pouco mais de $20 \mathrm{~cm}$ ] é branca. A ponta do chifre é afiada, vermelhão escuro, enquanto o restante, no meio, é preto. Dizem que quem bebe do chifre (que transformam em recipientes) fica imune a convulsões, à doença sagrada e não sofre efeitos do veneno, quer beba vinho, quer água ou qualquer outra coisa do recipiente antes ou depois de ingerir a droga" (Nichols, 2011, p. 56).

12 A esse respeito, veja o estudo clássico de Wittkoer (1942)

${ }_{13}$ Outra grande fonte para o imaginário do monstro e do monstruoso foi a Collectanea Rerum Memorabilium, de Solino (c. 200 EC).

14 Hist. Nat. VII. 1.6. Para um comentário detalhado da passagem sobre as raças monstruosas na História Natural de Plínio (Livro VII.1.6-4.36), veja Travillian (2015, p. 105). Todas as fontes de Plínio citadas na passagem são comentadas.
} 


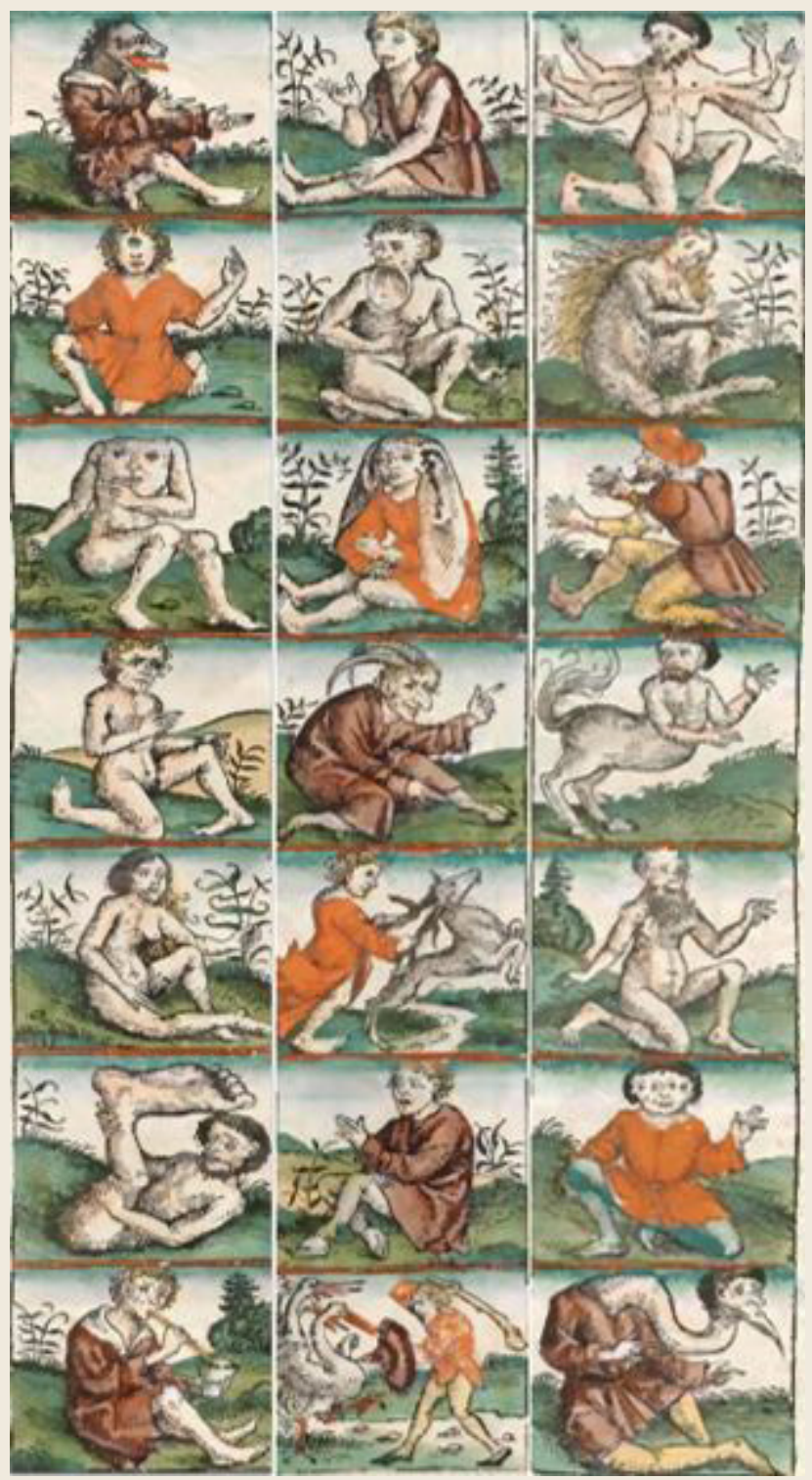

Figura 1 - Raças monstruosas.

Fonte: Pleydenwurff (1493).

Em virtude das muitas caracterizações construídas em torno de assombrosos estereótipos, Plínio contribuiu grandemente para o imaginário em torno da figura bárbara, não civilizada. Em outro exemplo, ao falar dos nômades das estepes conhecidos como citas, a alteridade é construída na base da selvageria: "saliento que algumas tribos citas se alimentam de corpos humanos" (Travillian, 2015, VII.9.1). Com retratos desse tipo, mesmo que herdados da tradição anterior, Plínio é quem seria apontado como o transmissor do conhecimento teratológico clássico e a origem das coloridas descrições sobre: arimaspos caolhos; ciápodes pezudos; andróginos; sciritos (os sem nariz); amictiros (com lábios inferiores em forma de prato); gnosofistas; abarimos dos pés virados para trás; panotes que tinham o rosto no peito e podiam se enrolar nas próprias orelhas; pigmeus; centauros; cinocéfalos; gente de pescoço comprido; hipópodes (que tinham cascos de cavalo); mulheres barbadas; figuras gêmeas de duas cabeças e quatro olhos. $\mathrm{E}$ a lista segue. Todas essas raças, como se nota, são definidas em oposição a uma normatividade. Embora seus corpos sejam constituídos ou possuam algumas partes humanas, a forma grotesca como estas se organizam no todo evidencia o processo de diferenciação que sustenta a norma. 


\section{Das bestas (in)conce bíveis - estratégias da diferenciação}

Alimentada, sobretudo, pela autoridade da teratologia de Plínio, a ideia de "maravilhas do Oriente", termo coletivo pelo qual os monstros passaram a ser referenciados, tornou-se popular. Tendo em vista que essas maravilhas forneciam uma moldura útil e viável para a taxonomia do diferente, autores cristãos da antiguidade tardia debateram sua existência e moralizaram sua natureza, com destaque para Agostinho. Com um capítulo inteiro de sua "Cidade de Deus" dedicado a questionar se certas raças monstruosas descenderiam de Adão, os argumentos do bispo de Hipona continuam a ser uma fonte importante para estudos sobre apreciações e atitudes da antiguidade tardia e do medievo sobre o tema. As questões centrais suscitadas pela discussão na "Cidade de Deus", como bem pontuadas por Knight (2018), são: monstros são naturais? Monstros servem a um propósito maior? Se sim, qual seria esse propósito? Se não, por quê? Agostinho descreve não cristãos como monstros?

\footnotetext{
Também é frequentemente perguntado se é de se acreditar que certos tipos monstruosos de seres humanos, descritos pela história pagã, foram gerados pelos filhos de Noé, ou antes, daquele único homem donde eles também nasceram. Entre estes, dizem que há alguns que têm um olho no meio da testa; entre outros, as solas dos pés estão viradas para trás, na direção das pernas; entre certas pessoas de ambos os sexos, é natural que a mama direita seja masculina, a esquerda feminina e, em coito umas com as outras, geram filhos; entre outros não há boca e eles vivem apenas respirando pelo nariz; outros têm um cúbito de estatura [cerca de $50 \mathrm{~cm}$ ], a quem os gregos chamam "pigmeus de cúbito"; em outros lugares as mulheres concebem aos cinco anos de idade e, na vida, não excedem os oito. Da mesma forma, eles afirmam que há pessoas que têm uma única perna sobre seus pés, não conseguem dobrar os joelhos e são incrivelmente rápidas. Elas são chamadas de "ciápodes" [monópodes], porque durante o verão, deitadas de costas no chão, se cobrem com a sombra dos pés. Certos homens sem pescoço têm os olhos nos ombros, e outros tipos de humanos, ou até quase-humanos, que são retratados em mosaico na esplanada de Cartago, derivam de livros de história ainda mais curiosa. O que devo dizer sobre os cinocéfalos, cujas cabeças de cães e latidos efetivos mostram que eles são mais bestas do que humanos? (Agostinho, 2017, XVI.8).
}

Com o recurso às raças anômalas do catálogo pliniano, que estão longe de se esgotar no excerto citado, Agostinho chega à conclusão de que, embora fosse possível duvidar da existência de todos os tipos descritos, qualquer um que tenha nascido em qualquer lugar como ser racional e mortal deriva do primeiro homem criado, "por mais estranho que seja para os nossos sentidos a forma do corpo, a cor, os movimentos, a voz ou mesmo as funções, partes ou qualidades da sua natureza" (Agostinho, 2017, XVI.8). Logo, tendo no horizonte as perguntas de Knight, de acordo com Agostinho, monstros não são contrários à natureza, pois não existem erros na criação de Deus. O propósito da sua existência é sinalizar outra coisa que não eles mesmos, no caso, os perigos do pecado. Nesse sentido, sendo parte do plano divino, as raças monstruosas eram um teste não apenas da devoção e piedade dos cristãos, mas também do seu compromisso ético com a criação: como descendentes de Adão, elas seriam merecedoras da salvação? Logo, além de oferecer uma série de justificativas para a existência desses seres bizarros, Agostinho daria o tom para o seu tratamento não só na antiguidade tardia, mas ao longo da Idade Média - Deus criou abundante e esteticamente; a causa e a função dos monstros são a sua glorificação.

O imaginário das raças monstruosas encontrou terreno muito fértil no medievo. Talvez seu melhor representante textual cristão seja Etimologias, de Isidoro de Sevilha. Se Agostinho fez circular o que pode 
ser entendido como uma apologia cristã do monstruoso, Isidoro editou o que seria a sua taxonomia cristã. O livro 11 das Etimologias ("O ser humano e os prodígios") trata dos monstros em detalhes e dá seguimento à tradição de situar essas estranhas criaturas em terras africanas e asiáticas, sempre ao norte e na periferia da civilização ${ }^{15}$.

Assim como em nações individuais há casos de povos monstruosos, também em toda a humanidade existem certas raças monstruosas, como os gigantes, os cinocéfalos (i.e., pessoas com cabeça de cachorro), os ciclopes e outras. [...] As pessoas acreditam que os blêmios, na Líbia, nascem com troncos sem cabeça, com boca e olhos no peito, e que outra raça nasce sem pescoço, com olhos nos ombros. Além disso, pessoas escrevem sobre os rostos monstruosos das nações do extremo Oriente: alguns sem nariz, com faces completamente planas e um semblante sem forma; alguns com o lábio inferior tão saliente que, quando dormem, protegem todo o rosto do calor do sol; alguns com bocas fechadas, nutrindo-se apenas através de uma pequena abertura, por meio de canudos. Dizem que alguns não têm línguas, usando acenos ou gestos no lugar das palavras. Eles falam dos panotes da Cítia, que têm orelhas tão grandes que cobrem todo o corpo [...]. Dizem que os artabatinos da Etiópia andam de quatro, como gado; ninguém passa dos quarenta anos (Barney, 2006, XI.3.12, 17, grifo nosso).

A conclusão de Isidoro sobre os monstros, assim como a de Agostinho antes dele, é que eles não são contra naturam, pois todas as coisas criadas por Deus são parte da natureza e fruto da sua vontade (Barney, 2006, XI.3.1-2).

A partir da disseminação das Etimologias na Europa Ocidental e Central, representações de raças monstruosas exóticas apareceram nas mais diversas mídias do medievo: nos catálogos de maravilhas, nas descrições e ilustrações das campanhas e feitos de Alexandre, o Grande, em cosmografias e crônicas do mundo, em enciclopédias de história natural, nos diários de viagem e, finalmente, nos mappae mundi. Essas representações carregam consigo uma invocação não apenas à imaginação e ao fantástico, mas também à credibilidade e à verdade. Em um estudo sobre metamorfose e identidade, Carolyn Walker Bynum conclui sua pesquisa e análise das teorias medievais do maravilhoso com a seguinte observação: "se você não acreditar no evento, não ficará maravilhado. Você pode se maravilhar somente com algo que está, pelo menos em algum sentido, aí" (Bynum, 2001, p. 73). Essa consciência do status problemático do valor da verdade relacionada às maravilhas, reiterada e complicada pelas imagens nessas mídias, pode ser bem ilustrada por dois episódios na obra "As Maravilhas do Oriente ${ }^{16}$, nos quais o ineditismo do que está sendo descrito é enfatizado. O primeiro deles fala de aves incendiárias. O segundo, de bestas de oito pés e duas cabeças.

Se qualquer homem quiser pegar ou tocá-las [as aves], elas queimam todo o seu corpo de uma só vez. Essas feitiçarias são inéditas.

Se qualquer homem quiser agarrá-las [as bestas], elas ateiam fogo em seus próprios corpos. Essas bestas são inéditas (Davidson, 1966, p. 54).

A retórica apresentada nas "Maravilhas" indica que muitas das criaturas fantásticas fugirão, matarão ou devorarão se forem tocadas, abordadas ou sequer perceberem a aproximação de pessoas. A

\footnotetext{
15 Para uma discussão da tipologia bíblica e greco-romana do Norte como lugar do mal e do monstruoso, bem como sua influência durante a Idade Média, veja Hope (2017)

16 Com manuscritos que datam do final do século 10 ao início do 11, "As Maravilhas do Oriente" se trata de um catálogo de povos, animais e coisas maravilhosas localizadas para além do mundo cultural europeu. Longe de alguma originalidade, os manuscritos das Maravilhas descrevem episódios individuais e maravilhas que também figuram em uma ampla gama de textos produzidos no período, que vão do "Liber Monstrorum" (séc. 7 ou 8) até o popular "As Viagens de Sir John Mandeville" (séc. 14). Para uma breve apresentação das Maravilhas e de outros escritos do período, veja Echard (2017, p. 1304).
} 
vívida reiteração dos perigos resultantes do contato sugere que sua existência não deve ser considerada aberta à verificação. Há que se manter distância, guardar as fronteiras contra esse "outro", mantê-lo em sua localização geográfica "apropriada", nas bordas da oikoumene, uma vez que um dos perigos da aproximação é perceber não tanto a diferença, mas o mesmo e, com isso, um alargamento indesejado da identidade com a consequente ampliação das fronteiras étnicas ${ }^{17}$.

\section{Da humanidade imperfeita - nãocristãos como outros monstruosos}

O Ocidente medieval herdou tanto a visão secular das monstruosidades orientais como também a religiosa, com a herança da antiguidade pagã sendo filtrada pelas lentes da autoridade bíblica. Nesse aspecto, como observado, Agostinho tentou conciliar essas maravilhas com a doutrina cristã: uma vez que somente Deus tem conhecimento e autoridade absolutos sobre sua criação, povos como os panotes (cujas enormes orelhas podiam cobrir todo o seu corpo), que são parte dela, não devem ser submetidos ao julgamento humano; como autor da criação, apenas Deus pode ver as semelhanças e diversidades que compreendem a beleza do todo.

Para Agostinho, o outro monstruoso parece ser muito mais do que uma condensação fictícia ou provisória de características que marcam diferenças entre uma humanidade diversa. As diferenças percebidas entre "nós e eles" funcionam como produto de distinções fundamentais que acompanham uma hierarquia da salvação. Dito de outra maneira, os outros, como humanidade imperfeita, representam o potencialmente recuperável (algo que lembra a compreensão da deficiência), pois todas as raças estão abertas à graça. Os monstros permanecem histórica e culturalmente separados da humanidade "normativa", embora potencialmente unificados com ela no momento do Juízo Final. Como encarnações de um ideal decaído, eles possuem um duplo status: insiders que desfrutam da promessa de salvação e outsiders que lembram à humanidade as consequências da queda - daí a importância da manutenção das fronteiras religiosas entre os de dentro e os de fora, uma vez que todos desempenham papeis bem marcados no jogo salvífico.

Qualquer binário, de acordo com o axioma de Derrida (2001), traduz-se em uma hierarquia ou relação violenta. No período medieval, a diferença era sempre hierárquica, com o outro em posição inferior ao que passava como normal - o que segue aplicável ao mundo contemporâneo. A crença e a adesão aos princípios e restrições do cristianismo marcavam a principal linha divisória entre os selvagens e os civilizados, metáforas convenientes para condenados e salvos. Portanto, não é nenhuma surpresa que Agostinho herde e faça uso do conceito de cidade como metáfora da civilização cristã ${ }^{18}$. Assim, na dinâmica da cidade e seus opostos, sarracenos ${ }^{19}$ e monstros foram relegados ao deserto (ou a uma cidade

\footnotetext{
17 Sobre identidade étnica e fronteiras étnicas, veja a teoria de Fredrik Barth em Poutignat e Streiff-Fernat (2011, p. 185). Para Barth, a identidade étnica (etnicidade) é continuamente negociada e (re)negociada tanto por atribuição externa como pela identificação interna. Isto é, identidade étnica é uma questão de autoatribuição (eu sou) e de atribuição feita por outros (reconhecido como). Nesse sentido, a identidade étnica é socialmente determinada, ao passo que a fronteira étnica é, derivativamente, uma fronteira social formada pela interação com os "outros".

${ }^{18}$ Também é pertinente mencionar o destaque da oposição cidade/deserto (região selvagem) no pensamento grego. A oposição entre civilizado e bárbaro se traduz como de dentro/de fora: na cidade-estado, um homem poderia alcançar a humanidade plena como "animal político" (Aristóteles); fora da cidade, a ilegalidade impedia a possibilidade de que ele realizasse sua completa humanidade. Dentro ele poderia ser um sujeito político. Fora, apenas um objeto curioso (White, 1985, p. 157; Williams, 2016, p. 10).

19 Termo empregado por cristãos medievais como referência genérica a árabes e/ou muçulmanos.
} 
metafórica de malfeitores), que a tradição cristã sempre associou à linhagem de Caim²0. Aliás, a cristandade medieval construiu para sarracenos uma alteridade monstruosa: a reunião de nações em Jerusalém, no Pentecostes, é normalmente retratada com um representante dos homens-cães, não raro servindo como substituto dos árabes ${ }^{21}$. Nas tradições oriental e ocidental da polêmica anti-muçulmana, sarracenos e cinocéfalos frequentemente apareciam associados (White, 1991). Os cristãos descreviam os muçulmanos como uma raça de cães que muitas vezes confrontava os cruzados em inúmeras hordas ${ }^{22}$. Sarracenos e homens-cães eram interpretados como animais selvagens, cujos desejos desviantes representam rejeição voluntária e perversão da verdade cristã23 ${ }^{3}$, denotando liberação inconveniente das restrições da religião e da convenção. Para os propagandistas, o simbolismo do sarraceno com cabeça de cão transmite as ideias de heresia religiosa, monstruosidade, afastamento e irracionalidade - em suma, o "outro".

\section{Conclusão}

Tendo como ponto de partida o imaginário antigo e medieval sobre raças monstruosas que povoavam as fronteiras da cultura, este texto buscou ensejar uma compreensão sobre o "outro" e sobre os limites imaginários que o criam e o separam do eu(nós) - limites esses fundados, inclusive, em releituras da tradição teológica cristã. Para todos os efeitos, monstro é um conceito multiuso bastante flexível, embora tudo o que ele designa convirja fundamentalmente em uma ideia: a de inumano, quaisquer que sejam as particularidades aí evocadas. Logo, apesar dos esforços apologéticos de Agostinho, é monstro o que não é humano, o incontrolável e intratável, seja no confronto de categorias com outras espécies, seja nos subterrâneos das relações performadas na nossa própria.

De corporeidade aberrante e excessiva, monstros são "outros inapropriados". Por outro lado, eles "significam", e por significarem desempenham um papel não (ou nem sempre) admitido na compreensão do eu(nós) e do seu lugar no mundo criado.

Monstros resumem, de muitas maneiras, concepções de alteridade. Um ritmo particular caracteriza sua existência: uma oscilação entre domesticação (negação da diferença) e estranhamento (reconhecimento da diferença). Eles podem, desse modo, ser enquadrados pela alegoria (exemplificação) e/ou distanciados pela obviedade da sua diferença.

Com a circunavegação do planeta e o reconhecimento de praticamente todas as terras habitadas, a geografia moderna pôs um fim ou pelo menos enfraqueceu a ideia de "bordas" do mundo e de lugares oníricos que acompanham esses limites. O mundo contemporâneo não guarda mais lugares longínquos e maleáveis povoados por criaturas fabricadas pela imaginação, mas incorpora variantes que

\footnotetext{
${ }^{20} \mathrm{Na}$ "Cidade de Deus", Agostinho lembra que Caim, após sua maldição, "construiu uma cidade" (Gn 4.17). O tipo de cidade que ele tinha em mente é representado pelo contraste entre os dois irmãos: "Dividi a humanidade em dois grandes grupos: um, o dos que vivem segundo o homem; o outro, o daqueles que vivem segundo Deus. Misticamente, damos aos dois grupos o nome de cidades, que é o mesmo que dizer sociedades de homens. Uma delas está predestinada a reinar eternamente com Deus; a outra, a sofrer eterno suplício com o diabo. [...] o primeiro filho dos dois primeiros pais do gênero humano foi Caim, pertencente à cidade dos homens, e o segundo, Abel, participante da Cidade de Deus. [...] diz a Escritura que Caim construiu uma cidade e Abel, como peregrino, nenhuma ergueu. Porque a Cidade dos santos está no céu [....]" (Agostinho, 2017, XV.1.1-2)

21 John Friedman associa o fundamento exegético para isso ao S/ 21.17, onde Davi grita em desespero que "os cães me cercaram; a assembleia dos ímpios me cercou; eles perfuraram minhas mãos e pés". Censurada como um ato irracional, a recusa do evangelho se tornou a imagem de judeus latindo ou de hereges rejeitando a verdade. Portanto, a presença de homens-cães para a sua disseminação atesta o poder de conversão da Palavra, uma vez que o mais intratável dos sujeitos poderia ser evangelizado (Friedman, 2000).

22 A mistura de sarracenos e cães ocorre nas canções de gesta francesas, em que os muçulmanos são representados latindo como cães quando entram na batalha (Jones, 1942).

${ }^{23}$ O mappa mundi Borgia retrata, no norte da África, um rei cinocéfalo dos sarracenos sentado em um trono, cortejado por dois súditos tão monstruosos quanto ele. A rubrica diz: "Abichinibel rex est Sarracenus Ethipicus; cum populo suo habens faciem caninam, et in cedente ornnes nudi propter solis calorem (Abichinibel é rei dos sarracenos etíopes; seu povo tem cara de cão e anda nu por causa do calor do sol). Para uma tradução de todas as rubricas, veja em: <https://is.gd/BorgiaMappaMundi>
} 
se movimentam no mesmo ritmo de oscilação entre domesticação e estranhamento na negociação das diferenças. Essas criaturas precisam existir, pois elas não somente oferecem uma forma segura de lidar com os terrores que assombram a mente humana, mas também e especialmente se comportam como salvaguarda para os limites normativos que as sociedades estabelecem. Na medida em que incorpora o monstro, o "outro", embora (desconfortavelmente) visível, está confinado à fronteira e define, por oposição, os padrões aceitáveis e saudáveis de sociedade. Trata-se, portanto, de um monstro com um papel, que pode epitomizar um (outro) grupo étnico, um (outro) grupo social, um (outro) grupo religioso - qualquer diferente.

Isso significa dizer que monstros nem sempre são as criaturas de corpos híbridos ou malformados que a mente desenha. Eles também podem ser identificados pela interação disruptiva com outros corpos, quer individuais, quer sociais/coletivos. Ao promoverem a perturbação da sua integridade, esses "outros" ameaçam e devem ser apartados da sociedade. Eles são outsiders familiares que operam como um lembrete constante de que as margens do corpo social (reflexo do individual) são frágeis e vulneráveis.

Além de atrair atenção imediata para o poder simbólico do corpo, a figura irregular e transgressiva do monstro ilustra o propósito histórico da sua existência: fornecer um lugar tangível para a exploração do problema sobre o que constitui uma identidade humana aceitável. Isso, porém, desnuda a saliência de uma contradição: o monstro tem que ser o outro, embora não possa sê-lo de maneira absoluta. Isto é, ao mesmo tempo em que é outro, o monstro ainda precisa ser e se manter reconhecível, familiar, sedutor e possível. Sem essa característica fundamental ele nada diz e perde sua função não apenas de demonstração, mas também de parâmetro da diferença e espelho da identidade, que é e sempre será relacional.

\section{Referências}

Agostinho. A cidade de Deus: contra os pagãos - Parte II (Livros XI a XXII). Petrópolis: Vozes, 2017.

Aristotle. Generation of Animals. London: William Heinemann, 1943.

Atherton, C. (ed.). Monsters and Monstrosity in Greek and Roman Culture. Bari: Levante, 1998. (Nottingham Classical Literature Studies 6).

Barney, S. A. et al. The Etymologies of Isidore of Seville. Cambridge: Cambridge University Press, 2006.

Bynum, C. W. Metamorphosis and identity. New York: Zone Books, 2001.

Bynum, C. W. Wonder. American Historical Review, n. 102, p. 1-26, 1997.

Crick, M. Explorations in language and meaning: towards a semantic anthropology. London: Malaby Press, 1976.

Davidson, D. D. Three Anglo-Saxon prose passages: a translation and commentary. 1966. Thesis (Master of Arts) - Faculty of Arts of the University of Otawa, Otawa, 1966.

Derrida, J. Posições. Belo Horizonte: Autêntica, 2001.

Echard, S.; Rouse, R. (ed.). The Encyclopedia of Medieval Literature in Britain. Chichester: John Wiley \& Sons, 2017. Friedman, J. B. The monstrous races in medieval art and thought. Syracuse: Syracuse University Press, 2000.

Garland, R. The eye of the beholder: deformity and disability in the Graeco-Roman world. 2nd. London: Bristol Classical Press, 2010.

Godden, R. H.; Mittman, A. S. (ed.). Monstrosity, disability, and the posthuman in the medieval and early modern world. London: Palgrave Macmillan, 2019.

Grixti, J. Terrors of uncertainty: the cultural contexts of horror fiction. London: Routledge, 1989. 
Hall, S. The work of representation. In: Hall, S. (ed.). Representation: cultural representations and signifying practices. London: SAGE Publications, 2003.

Hanciau, N. J. Entre-lugar. In: Figueiredo, E. (org.). Conceitos de literatura e cultura. Juiz de Fora: Editora UFJF, 2005. p. 125-161.

Haraway, D. The promises of monsters: a regenerative politics for inappropriate/d others. In: Weinstock, J. A. (ed.). The monster theory reader. Minneapolis: University of Minnesota Press, 2020. p. 459-521.

Hope, S. Typologies of the medieval cultural border. Roda da Fortuna: Revista Eletrônica sobre Antiguidade e Medievo, v. 6, n. 1, p. 25-54, 2017.

Hughes, B. A historical sociology of disability: human validity and invalidity from antiquity to early modernity. New York: Routledge, 2019.

Jones, C. Meredith: The conventional saracen of the songs of Geste. Speculum, n. 17, p. 201-225, 1942.

Knight, G. St. Augustine of Hippo, City of God - Selections (XVI.vii-ix; XXI.vii-viii). In: Mittman, A. S.; Hensel, M. (ed.). Primary Sources on Monsters. Leeds: Arc Humanities Press, 2018. p. 55-60.

McCrindle, J. W. (ed.). Ancient India as described by Mehasthênes and Arrian. Calcutta: Thacker, Spink \& Co, 1877.

Metzler, I. A Social history of disability in the Middle Ages: cultural considerations of physical impairment. New York: Routledge, 2013.

Nichols, A. G. Ctesias: on India and fragments of his minor works. London: Bloomsbury, 2011.

Peck, A. L. (ed.). Aristotle: generation of animals. Cambridge: Harvard University Press, 1953.

Pleydenwurff, W. Liber Chronicarum. Nürnberg: [s. n.], 1493. Doi: https://doi.org/10.11588/diglit.8305\#0001.

Poutignat, P.; Streiff-Fernat, J. Teorias da etnicidade: seguido de Grupos étnicos e suas fronteiras de Fredrik Barth. 2. ed. São Paulo: Ed. Unesp, 2011.

Rood, T. Herodotus and the foreign lands. In: Dewal, C.; Marincola, J. (ed.). The Cambridge Companion to Herodotus. Cambridge: Cambridge University Press, 2006. p. 290-305.

Silva, T. T. A produção social da identidade e da diferença. In: Silva, T. T. (org.). Identidade e diferença: a perspectiva dos estudos culturais. 15. ed. Petrópolis: Vozes, 2014. p. 73-102.

Stiker, H.-J. A History of disability. Ann Harbor: The University of Michigan Press, 1999.

Travillian, T. T. (ed.). The Natural History Book VII (with Book VIII, 1-34). London: Bloomsbury, 2015.

Watson, A. (ed.). The digest of Justinian. Philadelphia: University of Pennsylvanian Press, 1998. v. 4.

White, D. G. The myths of the dog-man. Chicago: University of Chicago Press, 1991.

White, H. Tropics of discourse: essays in cultural Criticism. Baltimore: Johns Hopkins University Press, 1985.

Williams, G. H. Wilderness and paradise in Christian thought: the biblical experience of the desert in the history of Christianity and the paradise theme in the theological idea of the university. Eugene: Wipf and Stock Publishers, 2016.

Wittkower, R. Marvels of the east: a study in the history of monsters. Journal of the Warburg and Courtauld Institutes, v. 5, p. 159-197, 1942.

Woodward, K. Identidade e diferença: uma introdução teórica e conceitual. In: Silva, T. T. (org.). Identidade e diferença: a perspectiva dos estudos culturais. 15. ed. Petrópolis: Vozes, 2014. p. 7-72.

Como citar este artigo/How to cite this article

Soares, E. A. Monstros nas fronteiras da cultura: das alteridades impensáveis. Reflexão, v. 46, e215533, 2021. https:// doi.org/10.24220/2447-6803v46e2021a5533 